\title{
Pituitary volume, stress reactivity and genetic risk for psychotic disorder
}

\author{
Citation for published version (APA):
}

Habets, P., Collip, D., Myin-Germeys, I., Gronenschild, E., van Bronswijk, S., Hofman, P., Lataster, T., Lardinois, M., Nicolson, N. A., van Os, J., \& Marcelis, M. (2012). Pituitary volume, stress reactivity and genetic risk for psychotic disorder. Psychological Medicine, 42(7), 1523-1533.

https://doi.org/10.1017/S0033291711002728

Document status and date:

Published: 01/07/2012

DOI:

10.1017/S0033291711002728

Document Version:

Publisher's PDF, also known as Version of record

Document license:

Taverne

\section{Please check the document version of this publication:}

- A submitted manuscript is the version of the article upon submission and before peer-review. There can be important differences between the submitted version and the official published version of record.

People interested in the research are advised to contact the author for the final version of the publication, or visit the DOI to the publisher's website.

- The final author version and the galley proof are versions of the publication after peer review.

- The final published version features the final layout of the paper including the volume, issue and page numbers.

Link to publication

\footnotetext{
General rights rights.

- You may freely distribute the URL identifying the publication in the public portal. please follow below link for the End User Agreement:

www.umlib.nl/taverne-license

Take down policy

If you believe that this document breaches copyright please contact us at:

repository@maastrichtuniversity.nl

providing details and we will investigate your claim.
}

Copyright and moral rights for the publications made accessible in the public portal are retained by the authors and/or other copyright owners and it is a condition of accessing publications that users recognise and abide by the legal requirements associated with these

- Users may download and print one copy of any publication from the public portal for the purpose of private study or research.

- You may not further distribute the material or use it for any profit-making activity or commercial gain

If the publication is distributed under the terms of Article $25 \mathrm{fa}$ of the Dutch Copyright Act, indicated by the "Taverne" license above, 


\title{
Pituitary volume, stress reactivity and genetic risk for psychotic disorder
}

\author{
P. Habets ${ }^{1} \dagger$, D. Collip ${ }^{1} \dagger$, I. Myin-Germeys ${ }^{1}$, E. Gronenschild ${ }^{1}$, S. van Bronswijk ${ }^{1}$, P. Hofman ${ }^{2}$, \\ T. Lataster ${ }^{1}$, M. Lardinois ${ }^{1}$, N. A. Nicolson ${ }^{1}$, J. van Os $^{1,3}$ and M. Marcelis ${ }^{1 *}$ for G.R.O.U.P. \\ ${ }^{1}$ Department of Psychiatry and Psychology, School for Mental Health and Neuroscience, EURON, Maastricht University Medical Center, \\ Maastricht, The Netherlands \\ ${ }^{2}$ Department of Radiology, Maastricht University Medical Center, Maastricht, The Netherlands \\ ${ }^{3}$ King's College London, King's Health Partners, Department of Psychosis Studies, Institute of Psychiatry, London, UK
}

\begin{abstract}
Background. Hypothalamic-pituitary-adrenal (HPA) axis hyperactivity, associated with increased pituitary volume, may mediate observed alterations in stress reactivity in patients with psychotic disorder. We examined the association between pituitary volume, real-life stress reactivity and genetic liability for psychotic disorder.
\end{abstract}

Method. Pituitary volumes were derived from magnetic resonance imaging (MRI) scans of 20 patients with psychotic disorder, 37 non-psychotic siblings of these patients, and 32 controls. The Experience Sampling Method (ESM) was used to measure emotional stress reactivity [changes in negative affect (NA) associated with daily life stress] in the three groups, and biological stress reactivity (changes in cortisol associated with daily life stress) in siblings and controls. Interactions between group, stress and pituitary volume in models of NA and cortisol were examined.

Results. Groups did not differ in pituitary volume. Patients showed significantly higher emotional stress reactivity than siblings and controls. In addition, emotional stress reactivity increased with increasing pituitary volume to a greater degree in patients than in controls and siblings. Siblings had higher cortisol levels than controls but did not show increased cortisol reactivity to stress. There was no interaction between pituitary volume, stress and group in the model of cortisol.

Conclusions. Higher pituitary volume was associated with increased emotional stress reactivity in patients with psychotic disorder, siblings and controls. The association was significantly stronger in the patient group, suggesting a process of progressive sensitization mediating clinical outcome.

Received 11 March 2011; Revised 22 August 2011; Accepted 1 November 2011; First published online 1 December 2011

Key words: Genetic predisposition to disease, hypothalamo-hypophyseal system, magnetic resonance imaging, pituitary-adrenal system, pituitary gland, psychological stress, schizophrenia, stress.

\section{Introduction}

Altered volumes of the pituitary gland have been associated with increased vulnerability for psychotic disorder (Garner et al. 2005). Patients with a first episode of psychosis (FEP) display increased pituitary volume, compared to controls (Pariante et al. 2005; Takahashi et al. 2009), as do individuals with early prodromal signs and subsequent transition to psychotic disorder, compared to those who do not make the transition (Garner et al. 2005). In samples

* Address for correspondence: M. Marcelis, M.D., Ph.D., Department of Psychiatry and Psychology, Maastricht University Medical Center, PO Box 616 (Vijv1), 6200 MD Maastricht, The Netherlands.

(Email : M.Marcelis@maastrichtuniversity.nl)

$\dagger$ These authors contributed equally to this work. diagnosed with psychotic disorder, an inverse association has been reported between illness duration and pituitary volume (Pariante et al. 2004), although not consistently so (Upadhyaya et al. 2007). In addition, there is evidence for larger pituitary volume in firstdegree relatives of patients with psychotic disorder (Mondelli et al. 2008).

The occurrence of pituitary enlargement in prodromal and antipsychotic (AP)-naïve patients, and in their relatives, suggests that the enlargement is not due to AP medication. However, cross-sectional studies show positive associations between firstgeneration APs (FGAs) or prolactin-elevating secondgeneration APs (SGAs) and pituitary volume (Pariante et al. 2005; MacMaster et al. 2007) in FEP, although not all studies agree (Takahashi et al. 2009). In addition, a longitudinal study reported a dose-response effect of 
prolactin-sparing SGAs on pituitary volume, higher doses predicting reduced volume (Nicolo et al. 2010). The mixed findings possibly reflect the fact that the pituitary gland is a highly dynamic organ, with many factors impacting on its volume over time. For example, studies have shown that women have larger pituitary volumes than men (Doraiswamy et al. 1992), and that both endogenous and exogenous estrogens are associated with pituitary volume (Grams et al. 2010).

The pituitary gland is a crucial organ involved in the hypothalamic-pituitary-adrenal (HPA) axis stress response. In depression, increased pituitary volume is thought to reflect HPA axis hyperfunctioning. Exposure to stress activates the HPA axis through the release of corticotropin-releasing hormone $(\mathrm{CRH})$ in the hypothalamus, resulting in secretion of adrenocorticotropic hormone (ACTH) in the pituitary, stimulating the release of cortisol in the adrenal cortex. Cortisol, through a negative feedback mechanism, regulates HPA axis activity. Persistently elevated cortisol levels can impair the negative feedback mechanism (Walker \& Diforio, 1997), resulting in HPA axis hyperactivity. As a result of HPA axis hyperactivity, patients become more sensitive to stressors, referred to as stress sensitization (Collip et al. 2008).

Increased cortisol levels have been found in FEP patients (Ryan et al. 2004) and also in siblings of patients with psychotic disorder (Collip et al. 2011), and may predict transition to a clinical psychotic outcome in young individuals at risk (Walker et al. 2010). FEP patients in the acute phase also show nonsuppression of cortisol secretion in the dexamethasone suppression test and in the dexamethasone/CRH test (Herz et al. 1985; Lammers et al. 1995). There is also evidence that patients with psychotic disorder are more sensitive to daily life stressors, resulting in increased levels of stress-related negative emotions (Myin-Germeys et al. 2001) and psychotic experiences (Myin-Germeys et al. 2005). Genetic risk for psychotic disorder may also be associated with increased cortisol reactivity (Collip et al. 2011), although other evidence suggests a blunted cortisol response to metabolic and psychosocial stressors in patients (Marcelis et al. 2004; Brenner et al. 2009; van Venrooij et al. 2010).

To date, the association between pituitary volume and stress reactivity in psychotic disorder remains unclear. The present study is the first to examine pituitary volume in relation to cortisol levels and negative affect (NA) in the context of daily life stressors, using a genetically sensitive sample (patients at highest genetic risk, siblings of patients at higher than average genetic risk, and controls at average genetic risk). The hypothesis was that patients and, to a lesser extent, siblings would show increased emotional stress reactivity compared to controls, accompanied by larger pituitary volumes. Similarly, with regard to biological stress reactivity, we hypothesized that siblings would show increased cortisol reactivity, accompanied by larger pituitary volumes.

\section{Method}

\section{Subjects}

Data pertain to baseline measures of an ongoing longitudinal study in Maastricht, The Netherlands. Details on the selection procedures are described in a prior publication (Habets et al. 2010). The sample consisted of 20 patients with a psychotic disorder, 37 siblings of patients with psychotic disorder and 32 controls. Inclusion criteria were: (i) age 16 to 50 years, (ii) diagnosis of non-affective psychotic disorder and (iii) good command of the Dutch language.

Diagnosis was based on DSM-IV criteria (APA, 2000), assessed with the Comprehensive Assessment of Symptoms and History (CASH) interview (Andreasen et al. 1992). Patients' diagnoses were: schizophrenia $(n=11)$, schizo-affective disorder $(n=2)$, schizophreniform disorder $(n=1)$, brief psychotic disorder $(n=2)$, and psychotic disorder not otherwise specified $(n=4)$. The CASH was also used to confirm the absence of a diagnosis of non-affective psychotic disorder in the siblings, and the absence of a lifetime diagnosis of any psychotic disorder or any current affective disorder in the healthy controls. Six siblings and seven controls had a history of major depressive disorder, but none presented in a current depressive episode.

Participants were screened for the following magnetic resonance imaging (MRI) exclusion criteria: (i) brain injury with unconsciousness $(>1 \mathrm{~h}$ ), (ii) neurological diseases that might have affected brain structure/function, (iii) cardiac arrhythmia requiring medical treatment (iv), severe claustrophobia, (v) metal corpora aliena, and (vi) women with intrauterine device status or (suspected) pregnancy.

The study was approved by the standing ethics committee, and all the subjects gave written informed consent in accordance with the committee's guidelines.

\section{Measures}

The Positive and Negative Syndrome Scale (PANSS; Kay et al. 1987) was used to measure psychotic symptoms over the past 2 weeks. AP medication use was determined using reports from the participant's 
psychiatrist. Best-estimate lifetime (cumulative) AP use was determined by multiplying the number of days of AP use by the corresponding haloperidol equivalents and summing these scores for all periods of AP use. Estrogen exposure was determined by multiplying the number of months of contraceptive medication use by micrograms of estrogen (of the corresponding contraceptive) per month. Substance use was assessed with the Composite International Diagnostic Interview (CIDI), sections B-J-L (WHO, 1990). Use of cannabis and other drugs was assessed as reported frequency of use during the past 12 months and lifetime. Alcohol intake was calculated as the average number of weekly consumptions during the past 12 months and tobacco use as the average number of daily cigarettes during the past 12 months.

\section{Experience Sampling Method (ESM)}

The ESM is a random time-sampling self-assessment technique; studies have demonstrated the feasibility, validity and reliability of the ESM in general and patient populations (Csikszentmihalyi \& Larson, 1987; Myin-Germeys et al. 2009). Subjects received a digital wristwatch that emitted a signal 10 times a day on 6 consecutive days, at unpredictable moments between 07:30 and 22:30 hours. After each 'beep', subjects completed ESM self-assessment forms concerning current context, thoughts, emotions, and psychotic experiences. Subjects were instructed to complete their reports immediately after the beep, thus minimizing memory distortions. Reports were considered valid when subjects responded within 15 min after the beep, as determined by comparing the actual beep time with the reported time of completion. For inclusion in the analyses, a valid response to at least one-third of the emitted beeps was required (Delespaul et al. 2002).

\section{ESM measures}

In accordance with previous work, two different stress measures were computed: event stress and social stress (Myin-Germeys et al. 2001). In the event stress assessment, after each beep, the most important event that had occurred between the current and the previous beep was reported. This event was subsequently rated on a Likert scale $(-3=$ very unpleasant, $0=$ neutral, $3=$ very pleasant). The responses were recoded to allow high scores to reflect stress. In the social stress assessment, participants were asked to evaluate the social context when other persons were present, by rating on a Likert scale $(1=$ not true, $7=$ very true $)$ the item 'I don't like the company' and the subsequent item 'I would rather be alone'. The mean of these two items constituted the social stress scale. NA was assessed with five mood-related adjectives (down, guilty, insecure, lonely, anxious) scored on Likert scales $(1=$ not at all, $7=$ very) after each beep. These were reduced to a single measure of mean NA with factor analyses (Cronbach's $\alpha=0.86$ ).

\section{Salivary cortisol sampling}

After each ESM beep, siblings and controls collected a saliva sample with a cotton swab from a salivette tube (Salivette; Sarstedt, The Netherlands), placed the swab back in the salivette tube, and recorded the exact collection time. Samples were stored in subjects' home freezers until transport to the laboratory, where uncentrifuged samples were kept at $-20^{\circ} \mathrm{C}$ until analysis. Samples collected more than $15 \mathrm{~min}$ after the beep were excluded from the analysis. Salivary cortisol is a reliable and non-invasive measure of the free, unbound cortisol in blood. Radioimmunoassays were run in duplicate, using a tracer solution of cortisol3CMO coupled with 2-[ $\left.{ }^{125} \mathrm{I}\right]$ histamine and specific antibodies raised against cortisol-3CMO-BSA (Sulon et al. 1978) (Dr J. Sulon, University of Liège). The lower detection limit of the assay was $0.2 \mathrm{nmol} / 1$. The intraand inter-assay coefficients of variation were $<5 \%$ and $<12 \%$ respectively. All samples from an individual were analyzed in the same assay to reduce sources of variability. Samples with cortisol $>44 \mathrm{nmol} / \mathrm{l}$ $(n=0)$ were considered physiologically abnormal and were excluded from the statistical analysis. As AP medication impacts cortisol values, cortisol was only measured in siblings and controls.

\section{Stress reactivity}

Stress reactivity, as described in previous work, was conceptualized as emotional (Myin-Germeys et al. 2001) and biological fluctuations (Collip et al. 2011) associated with minor disturbances in daily life, based on ESM data. Emotional stress reactivity was defined as the change in NA in reaction to small daily life stressors; biological stress reactivity was defined as the change in cortisol level in reaction to these stressors. Within the ESM sampling framework, the level of stress refers to experience since the last beep whereas negative emotions refer to experience at the moment of the current beep; therefore, change in NA is measured in reaction to stress (stress reactivity) because stress precedes NA.

\section{MRI acquisition and processing}

Acquisition parameters of the MRI scans, acquired with a 3-T Siemens scanner, were as follows. For the modified driven equilibrium Fourier transform 
(MDEFT) sequence: 176 slices, $1 \mathrm{~mm}$ isotropic voxel size, echo time (TE) $2.4 \mathrm{~ms}$, repetition time (TR) $7.92 \mathrm{~ms}$, flip angle $15^{\circ}$, total acquisition time $12 \mathrm{~min}$ 51s. For the magnetization prepared rapid acquisition gradient echo (MP-RAGE) sequence developed for the Alzheimer's Disease Neuroimaging Initiative (ADNI): 192 slices, $1 \mathrm{~mm}$ isotropic voxel size, TE $2.6 \mathrm{~ms}$, TR $2250 \mathrm{~ms}$, flip angle $9^{\circ}$, total acquisition time $7 \mathrm{~min} 23 \mathrm{~s}$. For both sequences the matrix size was $256 \times 256$ and the field of view $256 \times 256 \mathrm{~mm}$. Two sequences were used because of a scanner update during data collection. The MP-RAGE and MDEFT sequences are very similar, but to prevent systematic bias, the total proportion of MP-RAGE scans (27\%) was balanced between groups.

\section{MRI preprocessing}

Scans were preprocessed with Freesurfer stable release v5.0. Technical details of these procedures are described in prior publications (Dale et al. 1999; Fischl et al. 1999).

\section{Volume measures}

Pituitary volumes were obtained after manual tracing using GIANT (General Image Analysis Tools developed by EHBMG; Gronenschild et al. 2010), a customized software program that allows tracing of regions of interest in triplanar view and calculation of volumes of interest. All tracings were carried out on the native images. Each pituitary was traced in all coronal slices where it could be visualized (Sassi et al. 2001). Pituitary volume (in $\mathrm{mm}^{3}$ ) was calculated by summing the areas of the relevant slices and multiplying by the voxel size. All images were traced by the same rater (S.B.), who was blind to group assignment. The intra-class correlation coefficient of repeated measurements, based on a training set of 15 scans, was $r=0.92$.

\section{Statistical analyses}

ESM and cortisol data were analyzed using multilevel regression techniques, taking into account the hierarchical structure of the data. Repeated momentary measurements (level 1) were nested in subjects (level 2) who were part of the same family (level 3). Given these three levels, data were analyzed using the XTMIXED multilevel random regression routine in Stata v. 11.0 (StataCorp, 2009). The $B$ values are the fixed regression coefficients of the predictors in the multilevel model. Interaction terms were evaluated by Wald tests (Clayton \& Hills, 1993). In case of significant interaction effects, stratified analyses were conducted to quantify group differences, using the Stata
MARGIN command to calculate the appropriate linear combinations from the model containing the interaction. All analyses were adjusted for the a priori hypothesized confounders age, sex, intracranial volume, estrogen exposure and scan type.

Group differences in pituitary volume were examined using multiple regression procedures, with pituitary volume as the dependent variable and group (dummy variable: $0=$ controls, $1=$ siblings, $2=$ patients) as the independent variable. Group differences in stress reactivity were assessed by multilevel analyses, with NA as the dependent variable and group, stress (event stress and social stress) and their interactions as the independent variables.

To test the hypothesis that group status modified the association between pituitary volume and stress reactivity, multilevel regression analyses were conducted with stress, pituitary volume and group, and their interaction terms, as independent variables, and $\mathrm{NA}$ as the dependent variable: $\mathrm{NA}=B 0+B 1$ (group) + $B 2$ (stress) $+B 3$ (volume) $+B 4$ (group $\times$ stress $)+B 5$ (group $\times$ volume $)+B 6($ stress $\times$ volume $)+B 7$ (group $\times$ stress $\times$ volume). The group $\times$ stress $\times$ volume interaction was fitted with controls as the reference category. Pituitary volume was entered both as a linear variable and as dummy variables representing the distribution of volume calculated at the 33rd and 66th percentiles of pituitary volume of the controls, allowing visualization of dose-response: 1 corresponds to $<33$ rd percentile (low pituitary volume), 2 to $\geqslant 33$ rd and $<66$ th percentile (medium pituitary volume), and 3 to $\geqslant 66$ th percentile (high pituitary volume).

The same pattern of analyses as described above was applied to the $\log$ transformed cortisol values, with $\ln$ cort as the dependent variable. Additional confounders were: time of cortisol sample, time squared, and recent consumption of food or tobacco (since previous beep). To test whether the mean cortisol level differed between the two groups, a regression model was estimated with $\ln$ cort as the dependent variable and group $(0=$ controls, $1=$ siblings) as the independent variable.

The association between pituitary volume and both exogenous estrogen and lifetime AP was investigated using multiple regression analysis.

\section{Power analysis}

Power calculations for the three-way interaction analyses were carried out by empirical statistical simulation in Stata (www.stata.com/support/faqs/ stat/power.html), as described previously (Habets et al. 2011). Effect sizes were based on previously published work in this area. The effect sizes for the association between group and NA and between stress 
and NA, and the interaction between group and stress, were adapted from Myin-Germeys et al. (2001). Similarly, effect sizes in the model of cortisol were adapted from Collip et al. (2011). The effect sizes for the other interactions were not known. Therefore, effect sizes of 0.2 standard deviation (s.D.) (small) were used for the patient versus control simulations, and effect sizes of 0.1 S.D. were used for the sibling versus control simulations. At an $\alpha$ of 0.05 , the three-way interaction analysis had a power of $56 \%$ to detect a significant difference between patients and controls and a power of $18 \%$ to detect a significant difference between siblings and controls. Therefore, the results of the three-way interactions measuring differences between siblings and controls are only described exploratively so as to generate hypotheses for future research and help to generate realistic power calculations based on published effect sizes in these groups.

\section{Sensitivity analysis}

Studies report an association between pituitary volume and illness duration in schizophrenia (Pariante et al. 2004; Tournikioti et al. 2007), with increased pituitary volume for FEP patients and decreased pituitary volume for patients with established illness (EIP). Therefore, explorative analyses were carried out separately in patients with an illness duration of $\leqslant 5$ years $(\mathrm{FEP} ; n=10)$ and $>5$ years $(\mathrm{EIP} ; n=10)$.

\section{Results}

\section{Descriptive analyses}

Groups were well matched on most demographic variables (Table 1). Patients smoked more cigarettes and cannabis and used more hard drugs (lifetime) than siblings and controls, with no difference between the latter two groups. Eighteen patients received AP medication (SGA: $n=2$; FGA: $n=16$ ). Furthermore, three patients and two controls used antidepressants and one patient and one control used benzodiazepines. Patients reported higher PANSS scores than controls and siblings, with no difference between the latter two groups (Table 1).

\section{Group differences in pituitary volume and emotional stress reactivity}

Mean pituitary volume did not differ significantly between groups (patients: $602.6 \mathrm{~mm}^{3}$, S.E. $=23.4$; siblings: $624.5 \mathrm{~mm}^{3}$, S.E. $=17.5$; controls: $624.4 \mathrm{~mm}^{3}$, S.E. $=18.0 ; B=5.34, p=0.76)$. There was a trend significant group $\times$ event stress interaction in the model of NA (Table 2), indicating that stress reactivity differed between groups. Stratified analyses revealed that patients had significantly higher levels of stress reactivity compared to both controls and siblings. For social stress, there was no significant interaction effect with group in the model of NA (Table 2).

\section{Interaction between genetic risk, emotional stress reactivity and pituitary volume}

In the model of NA, there was a significant social stress $\times$ volume (linear variable) interaction $\left(\chi^{2}=23.03\right.$, $p=0.00)$ and also a significant group $\times$ social stress $\times$ volume, the latter indicating that the association between pituitary volume and stress reactivity differed between groups $\left(\chi^{2}=20.13, p=0.00\right)$. Stratified analyses showed that, with increasing pituitary volume, stress reactivity was progressively greater in patients compared to both controls and siblings, with no difference between the latter two groups. Visualizing the effect over the three tertile groups of pituitary volume revealed progressively higher stress reactivity with progressively higher pituitary volume in all three groups, but most pronounced in patients (Table 3; Fig. 1). Stress reactivity was significantly higher in the high-volume compared to the lowvolume group in controls $\left(\chi^{2}=7.17, p=0.01\right)$, siblings $\left(\chi^{2}=5.34, p=0.02\right)$ and patients $\left(\chi^{2}=12.72, p=0.00\right)$. In patients, stress reactivity was also significantly increased in the medium-volume compared to the low-volume group $\left(\chi^{2}=30.62, p=0.00\right)$.

The event stress $\times$ volume interaction effect in the model of NA was not significant, nor was the group $\times$ event stress $\times$ volume (linear variable) interaction $\left(\chi^{2}=1.15, p=0.56\right)$ (Table 3$)$; however, effect sizes were directionally similar to those observed for social stress. The direction and significance of the results remained the same when estrogen exposure was removed as a confounding factor (results available upon request).

\section{Group differences in cortisol levels and biological stress reactivity}

Siblings had significantly higher cortisol levels than controls $(B=0.30, p=0.00)$. The group $\times$ stress interaction in the model of cortisol was not significant for either social or event-related stress (Table 2).

\section{Interaction between genetic risk, biological stress reactivity and pituitary volume}

The stress $\times$ volume interaction and the group $\times$ stress $\times$ volume interaction in the model of cortisol were not significant for either social $\left(\chi^{2}=1.04, p=0.31\right)$ or event-related stress $\left(\chi^{2}=1.49, p=0.22\right)$ (Table 3 ). 
Table 1. Subject demographics

\begin{tabular}{|c|c|c|c|c|}
\hline & $\begin{array}{l}\text { Controls } \\
(n=32)\end{array}$ & $\begin{array}{l}\text { Siblings } \\
(n=37)\end{array}$ & $\begin{array}{l}\text { Patients } \\
(n=20)\end{array}$ & $\begin{array}{l}\text { Test statistic, } \\
p \text { value }\end{array}$ \\
\hline Age (years), mean (S.D.) & $32.9(11.5)$ & $28.3(7.8)$ & $29.1(8.0)$ & $F=2.39, p=0.10$ \\
\hline Gender (male:female) & $10: 22$ & $14: 23$ & $11: 09$ & $\chi^{2}=2.97, p=0.23$ \\
\hline Completed education, mean (s.D.) & $5.8(1.8)$ & $5.3(2.2)$ & $4.7(1.8)$ & $F=5.65, p=0.00$ \\
\hline \multicolumn{5}{|l|}{ PANSS scores, mean (S.D.) } \\
\hline Positive scale & $7.4(1.3)$ & $7.5(1.1)$ & $12.4(5.2)$ & $F=10.03, p=0.00$ \\
\hline Negative scale & $8.0(0.2)$ & $8.3(1.0)$ & $10.8(3.3)$ & $F=9.22, p=0.00$ \\
\hline Disorganization scale & $10.2(0.4)$ & $10.2(0.5)$ & $13.4(4.1)$ & $F=8.71, p=0.00$ \\
\hline Excitement scale & $8.3(0.6)$ & $8.4(1.1)$ & $9.9(2.1)$ & $F=5.37, p=0.00$ \\
\hline Emotional distress & $9.5(2.5)$ & $9.9(2.3)$ & $14.2(5.0)$ & $F=7.59, p=0.00$ \\
\hline $\begin{array}{l}\text { Alcohol use past } 12 \text { months (units/week), } \\
\text { mean (S.D.) }\end{array}$ & $7.6(10.4)$ & $7.4(9.1)$ & $5.1(6.7)$ & $F=1.54, p=0.21$ \\
\hline $\begin{array}{l}\text { Cigarette use past } 12 \text { months (cigarettes/day), } \\
\text { mean (s.D.) }\end{array}$ & $1.5(4.7)$ & $1.9(4.7)$ & $12.8(11.9)$ & $F=6.51, p=0.00$ \\
\hline \multicolumn{5}{|l|}{ Cannabis use (total no. of times), mean (S.D.) } \\
\hline Past 12 months & $2.3(10.7)$ & $3.7(13.1)$ & $36.1(102.1)$ & $F=1.38, p=0.25$ \\
\hline Lifetime & $12.0(30.4)$ & $18.7(36.4)$ & $54.2(48.0)$ & $F=4.86, p=0.00$ \\
\hline \multicolumn{5}{|l|}{ Hard drug use (total no. of times), mean (s.D.) } \\
\hline Past 12 months & $16.5(77.6)$ & $0.0(0.0)$ & $9.5(32.9)$ & $F=1.48, p=0.23$ \\
\hline Lifetime & $1.2(5.1)$ & $2.8(10.3)$ & $32.9(71.5)$ & $F=2.62, p=0.06$ \\
\hline \multicolumn{5}{|l|}{ Antipsychotics (APs) } \\
\hline Type AP (typical:atypical) & & & $2: 16$ & \\
\hline $\begin{array}{l}\text { Haloperidol equivalents present state (per day), } \\
\text { mean (s.D.) }\end{array}$ & & & $2.4(1.9)$ & \\
\hline $\begin{array}{l}\text { Lifetime AP use (total exposure in } \\
\text { haloperidol equivalents), mean (s.D.) }\end{array}$ & & & $1444.9(1412.8)$ & \\
\hline Lifetime estrogen exposure (total in $\mu \mathrm{g}$ ), mean (S.D.) & $17589(31700)$ & $18474(29410)$ & $672(2013)$ & $F=9.24, p=0.00$ \\
\hline Scan type (MDEFT:ADNI) & $23: 09$ & $26: 11$ & $16: 04$ & $\chi^{2}=0.7, p=0.72$ \\
\hline
\end{tabular}

PANSS, Positive and Negative Syndrome Scale; MDEFT, modified driven equilibrium Fourier transform; ADNI, Alzheimer's Disease Neuroimaging Initiative; S.D., standard deviation.

$F / \chi^{2}$ and $p$ values refer to between-group differences.

\section{AP medication use and estrogen exposure in relation to pituitary volume}

Lifetime AP use did not predict pituitary volume $(B=1.04, p=0.19)$, nor did estrogen exposure $(B=0.00$, $p=0.48)$. There was no suggestive or significant interaction between group and estrogen exposure in the model of pituitary volume $\left(\chi^{2}=0.00, p=0.99\right)$. Women had larger pituitary volumes than men $(B=63.94$, $p=0.04$ ), but no group $\times$ gender interaction was apparent in the model of pituitary volume.

\section{Sensitivity analysis}

Although the results were not statistically significant, FEP patients had higher pituitary volumes [mean = $641.1 \mathrm{~mm}^{3}$, standard error (s.E.) $=33.79$ ] than controls, and EIP patients had lower pituitary volumes $\left(\right.$ mean $=564 \mathrm{~mm}^{3}$, s.E. $\left.=91.08\right)$ than controls. Post-hoc analyses revealed that the group $\times$ social stress $\times$ volume (linear variable) interaction was attributable predominantly to the $\operatorname{FEP}\left(\chi^{2}=22.66, p=0.00\right)$, whereas in the EIP this interaction was no longer seen, although effect sizes were directionally similar $\left(\chi^{2}=1.65\right.$, $p=0.44)$.

\section{Discussion}

There was no mean difference in pituitary volume among the three groups. Patients with psychotic disorder showed higher levels of emotional stress reactivity than siblings and controls. Emotional stress reactivity was moderated not only by group but also by pituitary volume. In all three groups, increased emotional stress reactivity was associated with higher pituitary volume, but this association was much more pronounced in the patient group, suggesting a process 
Table 2. Multilevel regression estimates of emotional and biological stress reactivity

\begin{tabular}{llll}
\hline & $\chi^{2}$ & $p$ & $B$ \\
\hline $\begin{array}{l}\text { Biological stress reactivity } \\
\text { (cortisol) }\end{array}$ & & & \\
$\quad$ Group $\times$ event stress & 0.22 & 0.64 & \\
$\quad$ Group $\times$ social stress & 0.56 & 0.45 & \\
Emotional stress reactivity & & & \\
(NA) & & & \\
$\quad$ Group $\times$ event stress & 5.47 & 0.06 & $\mathrm{C}=0.04^{*}, \mathrm{~S}=0.04^{*}$, \\
Group $\times$ social stress & 2.48 & 0.29 & $\mathrm{P}=0.07^{*}$ \\
\hline
\end{tabular}

NA, Negative affect; C, Controls; $S$, siblings; $P$, patients. $* p<0.05$

$\chi^{2}$ and $p$ values represent the results of the Wald test, testing the significance of stratified effects calculated from the model with the group $\times$ stress interaction on cortisol and NA respectively.

The $B$ coefficients represent the effect sizes of level of stress sensitivity compared to the reference level.

of progressive sensitization mediating clinical outcome.

\section{Emotional stress reactivity}

The finding of increased emotional stress reactivity in patients is in line with previous studies that have shown that minor stressors in the flow of daily life were associated with an increase in NA in individuals with a psychotic disorder (Myin-Germeys et al. 2001, 2009). Although there was no difference in pituitary volume between the groups, emotional stress reactivity was associated with a larger pituitary volume in all three groups, with a much more pronounced increase in the patients than in the other two groups (Table 3). More specifically, each unit increase in stress reactivity was associated with an increase in pituitary volume of 0.20 S.D. in the patients. This phenomenon may indicate a mechanism of stress sensitization in the patients and mediate the onset of psychotic disorder.

Stress sensitization occurs when early and/or frequent exposures to stressors alter the stress response system, sensitizing individuals to later stress, leading to increased biological and behavioral response to that stressor, even when less severe than the original stressor. Given that many environmental risk factors associated with psychotic disorder may be linked to stress, stress sensitization may represent a common mechanism linking multiple environmental exposures (Collip et al. 2008). For example, evidence suggests that patients with psychotic disorder who report previous exposure to childhood trauma (Lardinois et al. 2010) or other stressful life events (Myin-Germeys et al. 2003) show increased stress reactivity in daily life. Higher pituitary volume may be the result of differential functional states (e.g. increased stress reactivity/ hypercortisolism) or, vice versa, contribute causally to increased stress reactivity. However, as this is a crosssectional study, no definite conclusion can be drawn regarding the direction of this association. Post-hoc analyses revealed that FEP had higher and EIP had lower pituitary volumes than controls, in line with previous studies (Pariante et al. 2005; Upadhyaya et al. 2007). In addition, the association between increased stress reactivity and pituitary volume was confined to the FEP group. These observations are in agreement with the hypothesis of two biologically distinct pathways resulting in mean group differences between (i) type 1 psychotic disorder, characterized by high levels of positive symptoms and an episodic course (Myin-Germeys \& van Os, 2007; Lataster et al. 2010), in addition to high stress reactivity and associated larger pituitary volume, and (ii) type 2 psychotic disorder, characterized by high levels of negative symptoms, cognitive impairments and a chronic course (Robins \& Guze, 1970; Crow, 1980; Murray et al. 1992; van Os et al. 1999), in addition to low stress reactivity and smaller pituitary volumes. A larger study sample and a longitudinal design are needed to draw more definitive conclusions about underlying mechanisms and direction of effects.

\section{Biological stress reactivity}

Mean cortisol levels were higher in siblings than in controls, consistent with another study from our group (Collip et al. 2011). It has been suggested that elevated cortisol levels in patients with a diagnosis of psychotic disorder (Ryan et al. 2004; Mondelli et al. 2010) and their siblings reflect disturbances in the negative feedback regulation of the HPA axis (Phillips et al. 2006). A comparable observation in depression is that HPA axis hyperactivity is thought to reflect a lack of negative inhibitory feedback by circulating cortisol on the HPA axis, particularly at the level of pituitary cells producing $\mathrm{ACTH}$, leading to an increase in the size and number of these cells. Persistently elevated cortisol secretion could also lead to resistance of the glucocorticoid receptors for cortisol (Pariante, 2006).

Cortisol fluctuations in response to daily life stress, however, did not show a significant difference between siblings and controls, which does not agree with a previous study (Collip et al. 2011). The present analyses, although based on the same cohort as described by Collip et al. (2011), were carried out in individuals for whom MRI data were available, resulting in a sample size reduction. Thus, statistical 
Table 3. Negative affect (NA) and cortisol as a function of daily life stress and pituitary volume, stratified by group

\begin{tabular}{|c|c|c|c|c|c|c|c|c|c|c|c|}
\hline & \multicolumn{3}{|c|}{ Controls } & \multicolumn{3}{|c|}{ Siblings } & \multicolumn{3}{|c|}{ Patients } & \multirow[b]{2}{*}{$\chi^{2}$} & \multirow[b]{2}{*}{$p$} \\
\hline & $B$ & $p$ & $95 \% \mathrm{CI}$ & $B$ & $p$ & $95 \% \mathrm{CI}$ & $B$ & $p$ & $95 \% \mathrm{CI}$ & & \\
\hline \multicolumn{12}{|l|}{ NA } \\
\hline $\begin{array}{l}\text { Event stress } \times \text { pituitary } \\
\text { volume }\end{array}$ & 0.04 & 0.00 & 0.03 to 0.06 & 0.04 & 0.00 & 0.02 to 0.06 & 0.07 & 0.00 & 0.05 to 0.10 & 1.15 & 0.56 \\
\hline $\begin{array}{l}\text { Social stress } \times \text { pituitary } \\
\text { volume }\end{array}$ & 0.10 & 0.00 & 0.07 to 0.13 & 0.08 & 0.00 & 0.04 to 0.11 & 0.20 & 0.00 & 0.14 to 0.26 & 20.13 & 0.00 \\
\hline Low volume & 0.06 & 0.03 & 0.01 to 0.11 & 0.05 & 0.04 & 0.00 to 0.09 & 0.02 & 0.49 & -0.02 to 0.06 & & \\
\hline Medium volume & 0.10 & 0.00 & 0.05 to 0.15 & 0.05 & 0.24 & -0.03 to 0.12 & 0.38 & 0.00 & 0.26 to 0.50 & & \\
\hline High volume & 0.16 & 0.00 & 0.11 to 0.22 & 0.14 & 0.00 & 0.08 to 0.20 & 0.42 & 0.00 & 0.20 to 0.62 & & \\
\hline \multicolumn{12}{|l|}{ Cortisol } \\
\hline $\begin{array}{l}\text { Event stress } \times \text { pituitary } \\
\text { volume }\end{array}$ & 0.01 & 0.66 & -0.02 to 0.04 & -0.01 & 0.74 & -0.04 to 0.03 & & & & 1.49 & 0.22 \\
\hline $\begin{array}{l}\text { Social stress } \times \text { pituitary } \\
\text { volume }\end{array}$ & 0.00 & 0.97 & -0.07 to 0.06 & -0.04 & 0.31 & -0.12 to 0.04 & & & & 1.04 & 0.31 \\
\hline
\end{tabular}

CI, Confidence interval.

The $B$ values represent the effect sizes of stress reactivity compared to the reference level.

$\chi^{2}$ and $p$ values represent the results of the Wald test, testing the significance of stratified effects calculated from the group $\times$ stress $\times$ volume interaction in the models of NA and cortisol.

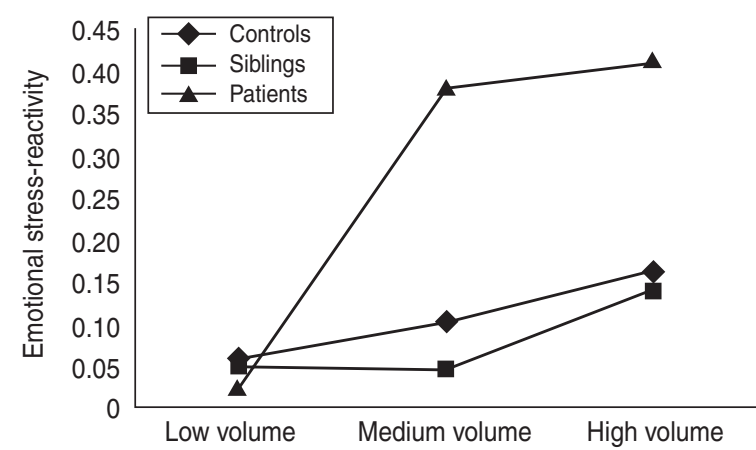

Fig. 1. Stress reactivity (expressed as $B$ coefficients) as a function of pituitary volume, stratified by group. Stress reactivity was significantly higher in the high-volume group when compared to the low volume in controls $(p=0.01)$, siblings $(p=0.02)$ and patients $(p=0.00)$. When comparing middle volume with low volume, only patients showed increased stress reactivity $(p=0.00)$. Patients showed higher stress reactivity when compared to controls in the medium pituitary volume group $(p=0.00)$ and in the high pituitary volume group $(p=0.02)$.

power was insufficient to detect small differences in cortisol reactivity between siblings and controls and/ or as a function of pituitary volume.

In conclusion, although some evidence for HPA axis hyperactivity was found in siblings (increased mean cortisol values), cortisol reactivity was not mediated by group status or pituitary volume in this study. Larger studies are needed before more definitive conclusions can be drawn. Nevertheless, the biological and emotional stress reactivity pathways seemed to be associated, as similar patterns in both biological and emotional stress reactivity were found in siblings and controls.

\section{Methodological considerations}

Some authors have cast doubt on the reliability and subject compliance in paper-and-pencil ESM studies, favoring the use of electronic devices (Stone et al. 2002). However, in a comparative study, Green et al. (2006) concluded that both methods yielded similar results.

Two different scanning sequences were used in this study, which could in theory have influenced the volume measurements. However, it has been shown that within-scanner measurements were reliable for subcortical volumes across scan sessions (Jovicich et al. 2009). Furthermore, no large or significant interaction was found between scan type and group on pituitary volume $\left(\chi^{2}=0.09, p=0.96\right)$. Similarly, adjusting the analyses for scanning sequence did not affect the direction or significance of the results.

Numerous external factors can influence pituitary volume, such as the use of APs. According to the study by Nicolo et al. (2010) in FEP, SGAs reduce pituitary gland volume in a dose-dependent manner. Other studies report that prolactin-elevating medication increases pituitary volume in comparison with 
prolactin-sparing medication (Pariante et al. 2005; Mondelli et al. 2008), but not all studies have found this association (Pariante et al. 2004; Takahashi et al. 2009). The present study did not find an association between cumulative lifetime exposure to AP medication and pituitary volume, but the groups were too small to examine differential effects of the AP group (SGA versus FGA). Adding lifetime AP medication as a confounder did not change the results (data available upon request).

Exogenous estrogen exposure has also been associated with pituitary volume. Reduced pituitary volumes have been found in women taking oral contraceptives (Grams et al. 2010) but, by contrast, elevated pituitary volumes have been found in menopausal women using estrogens (Abech et al. 2005). The present study did not find an association between lifetime estrogen exposure and pituitary volume. Larger studies investigating the association between estrogens and pituitary volume longitudinally are warranted. Nevertheless, there was a gender effect, in that pituitary volumes were higher in women than in men, possibly reflecting differences in endogenous estrogen levels (Doraiswamy et al. 1992). The role of estrogen in psychotic disorder remains unknown. Evidence suggests that estrogens may exert a neuroprotective effect and possibly have AP properties (Boerma et al. 2010). However, if estrogen could also lead to pituitary enlargement, this may potentially be less beneficial in terms of vulnerability for psychotic disorder. It is advisable to take estrogen measures into account when examining pituitary volumes.

\section{Acknowledgments}

This work was sponsored by the Netherlands Organization for Scientific Research (NOW), the European Community's Seventh Framework Programme under grant agreement HEALTH-F2-2009-241909 (EU-GEI consortium), and by a 2006 National Alliance for Research on Schizophrenia and Depression (NARSAD) Young Investigator Award and by the Dutch Medical Research Council (VENI and VIDI grant) to I. MyinGermeys.

We thank T. Driesen, I. Crolla and F. van Goethem for their assistance in this project as well as the G.R.O.U.P. investigators (R. Kahn, D. Linszen, J. van Os, D. Wiersma, R. Bruggeman, W. Cahn, L. de Haan, L. Krabbendam and I. Myin-Germeys).

\section{Declaration of Interest}

J. van Os is or has been an unrestricted research grant holder with, or has received financial compensation as an independent symposium speaker from, Eli Lilly,
BMS, Lundbeck, Organon, Janssen, GlaxoSmithKline, AstraZeneca, Pfizer, and Servier. M. Marcelis has received financial compensation as an independent symposium speaker from Eli Lilly and Janssen.

\section{References}

Abech DD, Moratelli HB, Leite SC, Oliveira MC (2005). Effects of estrogen replacement therapy on pituitary size, prolactin and thyroid-stimulating hormone concentrations in menopausal women. Gynecological Endocrinology 21, 223-226.

Andreasen NC, Flaum M, Arndt S (1992). The Comprehensive Assessment of Symptoms and History (CASH). An instrument for assessing diagnosis and psychopathology. Archives of General Psychiatry 49, 615-623.

APA (2000). Diagnostic and Statistical Manual of Mental Disorders, 4th edn, text revision (DSM-IV-TR). American Psychiatric Association: Washington, DC.

Boerma MA, van der Stel JC, van Amelsvoort T, Linszen DH, de Haan L (2010). Women, schizophrenia and estrogen; neurobiological hypotheses and hormone therapy studies [in Dutch]. Tijdschrift voor Psychiatrie 52, 235-244.

Brenner K, Liu A, Laplante DP, Lupien S, Pruessner JC, Ciampi A, Joober R, King S (2009). Cortisol response to a psychosocial stressor in schizophrenia: blunted, delayed, or normal? Psychoneuroendocrinology 34, 859-868.

Clayton D, Hills M (1993). Statistical Models in Epidemiology. Oxford University Press: Oxford.

Collip D, Myin-Germeys I, van Os J (2008). Does the concept of 'sensitization' provide a plausible mechanism for the putative link between the environment and schizophrenia? Schizophrenia Bulletin 34, 220-225.

Collip D, Nicolson NA, Lardinois M, Lataster T, van Os J, Myin-Germeys I (2011). Daily cortisol, stress reactivity and psychotic experiences in individuals at above average genetic risk for psychosis. Psychological Medicine 41, 2305-2315.

Crow TJ (1980). Molecular pathology of schizophrenia : more than one disease process? British Medical Journal 280, 66-68.

Csikszentmihalyi M, Larson R (1987). Validity and reliability of the Experience-Sampling Method. Journal of Nervous and Mental Disease 175, 526-536.

Dale AM, Fischl B, Sereno MI (1999). Cortical surface-based analysis. I. Segmentation and surface reconstruction. NeuroImage 9, 179-194.

Delespaul P, deVries M, van Os J (2002). Determinants of occurrence and recovery from hallucinations in daily life. Social Psychiatry and Psychiatric Epidemiology 37, 97-104.

Doraiswamy PM, Potts JM, Axelson DA, Husain MM, Lurie SN, Na C, Escalona PR, McDonald WM, Figiel GS, Ellinwood Jr. EH (1992). MR assessment of pituitary gland morphology in healthy volunteers: age- and genderrelated differences. American Journal of Neuroradiology 13, 1295-1299. 
Fischl B, Sereno MI, Dale AM (1999). Cortical surface-based analysis. II : Inflation, flattening, and a surface-based coordinate system. NeuroImage 9, 195-207.

Garner B, Pariante CM, Wood SJ, Velakoulis D, Phillips L, Soulsby B, Brewer WJ, Smith DJ, Dazzan P, Berger GE, Yung AR, van den Buuse M, Murray R, McGorry PD, Pantelis C (2005). Pituitary volume predicts future transition to psychosis in individuals at ultra-high risk of developing psychosis. Biological Psychiatry 58, 417-423.

Grams AE, Gempt J, Stahl A, Forschler A (2010). Female pituitary size in relation to age and hormonal factors. Neuroendocrinology 92, 128-132.

Green AS, Rafaeli E, Bolger N, Shrout PE, Reis HT (2006). Paper or plastic? Data equivalence in paper and electronic diaries. Psychological Methods 11, 87-105.

Gronenschild EH, Burgmans S, Smeets F, Vuurman EF, Uylings HB, Jolles J (2010). A time-saving and facilitating approach for segmentation of anatomically defined cortical regions: MRI volumetry. Psychiatry Research 181, 211-218.

Habets P, Marcelis M, Gronenschild E, Drukker M, van Os J (2011). Reduced cortical thickness as an outcome of differential sensitivity to environmental risks in schizophrenia. Biological Psychiatry 69, 487-494.

Herz MI, Fava GA, Molnar G, Edwards L (1985). The dexamethasone suppression test in newly hospitalized schizophrenic patients. American Journal of Psychiatry 142, 127-129.

Jovicich J, Czanner S, Han X, Salat D, van der Kouwe A, Quinn B, Pacheco J, Albert M, Killiany R, Blacker D, Maguire P, Rosas D, Makris N, Gollub R, Dale A, Dickerson BC, Fischl B (2009). MRI-derived measurements of human subcortical, ventricular and intracranial brain volumes: reliability effects of scan sessions, acquisition sequences, data analyses, scanner upgrade, scanner vendors and field strengths. NeuroImage 46, 177-192.

Kay SR, Fiszbein A, Opler LA (1987). The positive and negative syndrome scale (PANSS) for schizophrenia. Schizophrenia Bulletin 13, 261-276.

Lammers CH, Garcia-Borreguero D, Schmider J, Gotthardt U, Dettling M, Holsboer F, Heuser IJ (1995). Combined dexamethasone/corticotropin-releasing hormone test in patients with schizophrenia and in normal controls: II. Biological Psychiatry 38, 803-807.

Lardinois M, Lataster T, Mengelers R, van Os J, Myin-Germeys I (2010). Childhood trauma and increased stress sensitivity in psychosis. Acta Psychiatrica Scandinavica 123, 28-35.

Lataster T, Collip D, Lardinois M, van Os J, Myin-Germeys I (2010). Evidence for a familial correlation between increased reactivity to stress and positive psychotic symptoms. Acta Psychiatrica Scandinavica 122, 395-404.

MacMaster FP, El-Sheikh R, Upadhyaya AR, Nutche J, Rosenberg DR, Keshavan M (2007). Effect of antipsychotics on pituitary gland volume in treatment-naive first-episode schizophrenia: a pilot study. Schizophrenia Research 92, 207-210.

Marcelis M, Cavalier E, Gielen J, Delespaul P, van Os J (2004). Abnormal response to metabolic stress in schizophrenia : marker of vulnerability or acquired sensitization? Psychological Medicine 34, 1103-1111.

Mondelli V, Dazzan P, Gabilondo A, Tournikioti K, Walshe M, Marshall N, Schulze KK, Murray RM, McDonald C, Pariante CM (2008). Pituitary volume in unaffected relatives of patients with schizophrenia and bipolar disorder. Psychoneuroendocrinology 33, 1004-1012.

Mondelli V, Dazzan P, Hepgul N, Di Forti M, Aas M, D'Albenzio A, Di Nicola M, Fisher H, Handley R, Marques TR, Morgan C, Navari S, Taylor H, Papadopoulos A, Aitchison KJ, Murray RM, Pariante CM (2010). Abnormal cortisol levels during the day and cortisol awakening response in first-episode psychosis: the role of stress and of antipsychotic treatment. Schizophrenia Research 116, 234-242.

Murray RM, O'Callaghan E, Castle DJ, Lewis SW (1992). A neurodevelopmental approach to the classification of schizophrenia. Schizophrenia Bulletin 18, 319-332.

Myin-Germeys I, Delespaul P, van Os J (2005). Behavioural sensitization to daily life stress in psychosis. Psychological Medicine 35, 733-741.

Myin-Germeys I, Krabbendam L, Delespaul PA, van Os J (2003). Do life events have their effect on psychosis by influencing the emotional reactivity to daily life stress? Psychological Medicine 33, 327-333.

Myin-Germeys I, Oorschot M, Collip D, Lataster J, Delespaul P, van Os J (2009). Experience sampling research in psychopathology: opening the black box of daily life. Psychological Medicine 39, 1533-1547.

Myin-Germeys I, van Os J (2007). Stress-reactivity in psychosis: evidence for an affective pathway to psychosis. Clinical Psychology Review 27, 409-424.

Myin-Germeys I, van Os J, Schwartz JE, Stone AA, Delespaul PA (2001). Emotional reactivity to daily life stress in psychosis. Archives of General Psychiatry 58, 1137-1144.

Nicolo JP, Berger GE, Garner BA, Velakoulis D, Markulev C, Kerr M, McGorry PD, Proffitt TM, McConchie M, Pantelis C, Wood SJ (2010). The effect of atypical antipsychotics on pituitary gland volume in patients with first-episode psychosis: a longitudinal MRI study. Schizophrenia Research 116, 49-54.

Pariante CM (2006). The glucocorticoid receptor: part of the solution or part of the problem? Journal of Psychopharmacology 20, 79-84.

Pariante CM, Dazzan P, Danese A, Morgan KD, Brudaglio F, Morgan C, Fearon P, Orr K, Hutchinson G, Pantelis C, Velakoulis D, Jones PB, Leff J, Murray, RM (2005). Increased pituitary volume in antipsychotic-free and antipsychotic-treated patients of the Æsop first-onset psychosis study. Neuropsychopharmacology 30, 1923-1931.

Pariante CM, Vassilopoulou K, Velakoulis D, Phillips L, Soulsby B, Wood SJ, Brewer W, Smith DJ, Dazzan P, Yung AR, Zervas IM, Christodoulou GN, Murray R, McGorry PD, Pantelis C (2004). Pituitary volume in psychosis. British Journal of Psychiatry 185, 5-10.

Phillips LJ, McGorry PD, Garner B, Thompson KN, Pantelis C, Wood SJ, Berger G (2006). Stress, the 
hippocampus and the hypothalamic-pituitary-adrenal axis: implications for the development of psychotic disorders. Australian and New Zealand Journal of Psychiatry 40, 725-741.

Robins E, Guze SB (1970). Establishment of diagnostic validity in psychiatric illness: its application to schizophrenia. American Journal of Psychiatry 126, 983-987.

Ryan MC, Sharifi N, Condren R, Thakore JH (2004). Evidence of basal pituitary-adrenal overactivity in first episode, drug naive patients with schizophrenia. Psychoneuroendocrinology 29, 1065-1070.

Sassi RB, Nicoletti M, Brambilla P, Harenski K, Mallinger AG, Frank E, Kupfer DJ, Keshavan MS, Soares JC (2001). Decreased pituitary volume in patients with bipolar disorder. Biological Psychiatry 50, 271-280.

StataCorp (2009). Stata Statistical Software: Release 11. StataCorp LP: College Station, TX.

Stone AA, Shiffman S, Schwartz JE, Broderick JE, Hufford MR (2002). Patient non-compliance with paper diaries. British Medical Journal 324, 1193-1194.

Sulon J, Demey-Ponsart L, Beauduin P, Sodoyez JC (1978). Radioimmunoassay of corticosterone, cortisol and cortisone: their application to human cord and maternal plasma. Journal of Steroid Biochemistry 9, 671-676.

Takahashi T, Suzuki M, Velakoulis D, Lorenzetti V, Soulsby B, Zhou SY, Nakamura K, Seto H, Kurachi M, Pantelis C (2009). Increased pituitary volume in schizophrenia spectrum disorders. Schizophrenia Research 108, 114-121.
Tournikioti K, Tansella M, Perlini C, Rambaldelli G, Cerini R, Versace A, Andreone N, Dusi N, Balestrieri M, Malago R, Gasparini A, Brambilla P (2007). Normal pituitary volumes in chronic schizophrenia. Psychiatry Research 154, 41-48.

Upadhyaya AR, El-Sheikh R, MacMaster FP, Diwadkar VA, Keshavan MS (2007). Pituitary volume in neuroleptic-nai ve schizophrenia: a structural MRI study. Schizophrenia Research 90, 266-273.

van Os J, Gilvarry C, Bale R, Van Horn E, Tattan T, White I, Murray R (1999). A comparison of the utility of dimensional and categorical representations of psychosis. UK700 Group. Psychological Medicine 29, 595-606.

van Venrooij JA, Fluitman SB, Lijmer JG, Kavelaars A, Heijnen CJ, Westenberg HG, Kahn RS, Gispen-de Wied CC (2010). Impaired neuroendocrine and immune response to acute stress in medication-naive patients with a first episode of psychosis. Schizophrenia Bulletin. Published online: 17 June 2010. doi :10.1093/schbul/ sbq062.

Walker EF, Brennan PA, Esterberg M, Brasfield J, Pearce B, Compton MT (2010). Longitudinal changes in cortisol secretion and conversion to psychosis in at-risk youth. Journal of Abnormal Psychology 119, 401-408.

Walker EF, Diforio D (1997). Schizophrenia: a neural diathesis-stress model. Psychological Review 104, 667-685.

WHO (1990). Composite International Diagnostic Interview (CIDI). World Health Organization: Geneva. 